\title{
A STUDY ON DIGITALIZATION AND TECHNOLOGY ENVIRONMENT AND ITS IMPACT ON BANKS
}

\author{
Sumeet Kaur \\ ${ }^{* *}$ Harneet Kaur \\ **** Narender Singh
}

\begin{abstract}
Banking system plays a very dominant role in the Indian economy. It is like a principal nerve to the nation's economy as it serves to the financial requirements of credit in all the spheres of the society. The growth and innovations in technology has led to a paradigm shift in the entire banking operations and systems. The digital revolution is dramatically changing the business environment and the financial services industry is no exception. Moreover, the evolution of e-banking has led to the substantial change in terms of fulfilling customers' divergent and ever growing needs. Further, our government is giving a lot of thrust to digital banking as it is the future of tomorrow. The present study explores the influence of technology in banking sector among customers by reviewing the relevant literature from the earlier studies. An extensive study on the impact of technology on banking, highlights the factors such as effectiveness of data management, value added services, level of knowledge and awareness, security, safety, service quality, productivity, and profitability.

Keywords: Core Banking; Digital Revolution; E-Banking; Digital Banking; Value added Services; Service Quality.
\end{abstract}

\section{Introduction}

An industry that has seen gigantic developments as of late is the utilization of innovation inside the monetary world. The new trendy expression 'FinTech' is getting to be regular place in the segment and with a consistently developing corporate and shopper center, the need to stay aware of headways is seeing more decision and an enhanced client encounter over the sheets.

\begin{abstract}
Managing an account was generally something that was done in the non-virtual world. Individuals would go into town to their bank to pull back cash, exchange assets starting with one place then onto the next, and deal with their funds. You'd address a supportive staff part and associate with individuals in a physical building. Be that as it may, these sorts of premises are quickly getting to be excess. Internet keeping money is getting increasingly refined once a day - we can exchange cash or pay for merchandise with simply pressing the button.
\end{abstract}

There are several sites, by which we can switch between banks and get the products or services as per our requirements; such types of benefits are limitless. Today the world is too much hi tech that we can access our bank account anywhere by using phones, computers and tablets. Although it is advantageous for us, but its other side is not so good as it creates problems in banking sector by disrupting their functionality. Hence we can say that digitalization and more use of technology is affecting a lot the industry and consumers.

Digital Banking might be seen as selection of different existing and rising advances by the banks, working together with related changes in interior activities and also outside connections for giving prevalent client administrations and encounters viably and effectively.

Today, every field is under the impact of technology; hence, we can assume ourselves living in a digital wonderland. Moreover we hope that the milkman accepts wallet payment without a fuss, a man buys a geometry set worth about Rs 100 for his daughter using a credit card and the vegetable vendor uses QR code based "Scan \& Pay" utility. 
The new innovative digital technologies and futuristic thought processes have given birth to whole new businesses and social dimensions. Projects such as Make in India and Digital India are now the buzzwords to a bright and sustainable industrial and financial progress of our nation. As part of its impetus for Digital Transformation in India, Government also encourages technology adoption / up gradation while providing connectivity with high speed bandwidth to every nook and corner of the country. This has exposed the full potential of the hitherto untapped market in India. Latest technology and service offerings in the new age Digital Payments space by the Banks, such as Unified Payments Infrastructure (UPI) including BHIM (Bharat Interface for Money) which is a Mobile App developed by National Payments Corporation of India (NPCI), Bharat Bill Payment System (BPSS), mobile money, e-wallets, payment aggregation etc. have created a revolution by themselves.

\section{Digital Banking - A Boon or Bane}

Passing by the profound infiltration inside a generally lesser turnaround time, best in class advanced installment frameworks are currently ready to take quantum jumps in this new period that is to a great extent driven by the pervasive Internet. These problematic elements and income models are truly the new distinct advantages causing unmistakable and strategic moves crosswise over significant verticals. Internet business and M-trade achievement is to a great extent credited to the wonderful development of different computerized installment innovations, for example, card installments, electronic store exchanges, installment doors, ePayments, brilliant cards, portable cash wallets and so forth. Urgent to grasping such new age installment frameworks are the general population, innovations, and procedures that have together made tremendous, vigorous and tried and true systems and consistent frameworks that ensure humongous value-based volumes dangerously fast, with tried and true security and counterchecks worked around them.

All these and rest are taking India to the edge of the major group and to make the nation fight prepared to contend with the most persuasive mechanical and money related forces of worldwide organizations. With computerized keeping money and versatility, the need is no longer to "jump frog" however to "profound plunge" into what's to come. Going computerized and versatile for a Bank is never again a choice, it's a basic minimum essential - to team up and thrive. The present testing advanced installments environment has turned into a blossoming commercial center.
Banks have just begun assessing the decrease in number and size of branches (both the quantity of units and the span of existing offices). What's more, the interest in computerized innovation to supplant more costly human collaborations is likewise being considered. This incorporates, however not constrained to, tablets for all inclusive brokers, robotized teller machines and advanced stands to encourage account opening and client request. To be effective in a computerized situation, banks center around enhancing their advanced development crosswise over different elements of client benefit.

\section{Review of Literature}

Anna Omarini et al., (2017) One of the primary changes in the business is getting to be digitalization which is seeing a significant change to the managing an account framework. Digitalization offers new open doors for banks to put the client at the focal point of the improvement procedure. New innovations appear to be and remain in the market to upset the retail money related administration esteem chain, and also bringing new players into the focused field. Officeholders and new comers have creative switches to embrace. The powers molding these progressions have come out on top to reevaluate the job of managing an account and back, additional as an "empowering influence" than a supplier of items and administrations. The goes for characterizing computerized change in the keeping money industry, delineating what banks and FinTech organizations are both creating in the market, and furthermore calling attention to that it won't be simply the innovation that will be the disruptor of the managing an account industry, yet rather how firm conveys the innovation that will cause the interruption.

D S Chaubey et al., (2017) The effect of advanced innovation in keeping money and monetary administrations over the previous decade reflects the extraordinary effect on the economy all in all. To address out the developing difficulties of economy and to accelerate the business budgetary exchanges the managing an account part has changed itself as per the socio-conservative standards and grasped the utilization of innovation to serve its customers quicker with the end goal to expand the keeping money base with controlled installment repayment frameworks. Industry pioneers are attempting their best to decide the ramifications of these changes. Regularly developing innovative upset has deliberately combined the keeping money industry and changed its bookkeeping and administration framework which affected proficient and quick installment repayment inside and outside the political limit. Upset current keeping money is presently centering 
to limit the utilization of money in the public arena and proceeded with its undertakings to enhance the IT foundation with a view to encourage the Indian managing an account segments arrangement with the most recent mechanical advancements. Therefore this shows an examination which means to break down the RBI activities and job of data innovation in saving money industry particularly in setting to expedient installment repayment framework as indicated by the strategies methods laid by the summit body Reserve Bank of India (RBI).

A K Rathi et al., (2016) Digital Transformation is a long ways past simply moving from conventional keeping money to a computerized world. It is a crucial change in how banks and other budgetary organizations find out about, interface with and fulfill clients. An effectual Digital Transformation starts with a comprehension of advanced client conduct, inclinations, decisions, likes, despises, expressed and additionally implicit requirements, desires and so forth.. What's more, this change prompts the significant changes in the associations, from item driven to client driven view. An investigation by CGI entitled, Understanding Financial Consumers in the Digital Era reveals some insight into the wants of the present computerized purchaser. Strikingly, when money related organizations appear to be in a bolt venture with one another, buyers are increasing current standards on their desires. Furthermore, as indicated by the investigation by CGI, they will leave where they as of now bank if their necessities are not met.

P K Ozili et al., (2018) This gives an exchange on a few issues related with advanced fund - a territory which has not been basically tended to in the writing. Computerized back and money related consideration has a few advantages to budgetary administrations clients, advanced fund suppliers, governments and the economy; in any case, various issues still hold on which whenever tended to can improve computerized fund work for people, organizations and governments. The advanced fund issues examined in this are applicable for the ongoing discussion and nation level activities coordinated at more prominent budgetary incorporation by means of computerized back in creating and rising economies.

S Lewis et al., (2015) Banks have been compelled to deleverage and recognize elective wellsprings of significant worth because of expanded controls and focused difficulties. This has prompted the presentation of computerized saving money where innovation is for the most part grasped while conveying exchanges. Nonetheless, clients are as yet sitting tight for this new managing an account understanding, touted as a progressive change that will bring numerous new highlights, including whenever and anyplace saving money, ultra-quick reaction times, and ubiquitous consultants. This examination purposed to explore the impact of computerized putting money on consumer loyalty instance of National Bank of Kenya Bungoma County. Four targets that guided the investigation: To decide the impacts of speed of exchanges, to survey impacts of availability, to decide impacts of flexibility of computerized keeping money and to set up how moderateness of advanced managing an account impacts Customer Satisfaction instance of National Bank of Kenya, Bungoma County. The objective populace for the examination was bank clients and managing an account staff from National Bank in Bungoma County. The examination used an example size of 417 with 42 respondents being a piece of the pilot ponder embraced. Illustrative overview configuration was embraced. Information was gathered utilizing a triangulation of strategies including polls, talk with calendars and report audits. Investigation was attempted with the guide of Statistical Package for Social Sciences where both spellbinding and connection examination were performed.

\section{Advantages of Digitalization in Banking}

Digitization is the transformation of information into a computerized arrangement with the appropriation of innovation. By grasping digitalization, banks can give upgraded client administrations. This gives accommodation to clients and aides in sparing time. Digitalization decreases human blunder and along these lines manufactures client devotion. Today, individuals have nonstop access to banks because of internet saving money. Overseeing a lot of money has additionally turned out to be less demanding. Digitalization has additionally profited clients by encouraging cashless exchanges. Clients require not store money any longer and can make exchanges at wherever and time.

Computerized change appears to be unique in each industry and each organization. By and large terms, it is the coordination of advanced innovation into all zones of a business. That mix prompts basic changes in how the business works and conveys an incentive to its clients.

Banks running on an advanced center can see lessened expenses and streamlined procedures. This conclusion to-end reconciliation likewise gives a more consistent, connecting with client encounter. Also, it prepares for further business change with new computerized advances like blockchain and man-made consciousness. 
Going advanced has likewise influenced the managing an account workforce, with mechanization here and there bringing about cutbacks and staff decreases. Be that as it may, there is a developing interest for information researchers with keeping money encounter-a range of abilities difficult to discover in the present market. It is the ideal opportunity for the business to build up another workforce model to instruct existing staff and enlist new ability.

\section{Conclusion}

So with regards to picking an approach to give monetary administrations to individuals, the decision is unfortunately evident and numerous organizations are concerned they will miss out to the trailblazers in this segment in the event that they don't grasp these improvements.

FinTech can be a more compelling approach to work. The advantages of instinct, ad lib and different things that machines can't do are exceeded by what they can. The most noteworthy factor is dealing with the harmony among innovation and manual mediation, and how fitting this will additionally reform the business for the two organizations and shoppers. Late demonetisation exercise of higher category notes by the legislature has extremely quickened the change of advanced saving money in India. Development in the quantity of computerized exchanges has been exponential since November 2016. Supported by Government pushed, individuals of India at long last appear to have acknowledged/grasped computerized economy. Interest for money is reducing gradually. New instalment activities, for example, Aadhaar-connected cashless instalment arrangement which empowers a vendor to encourage Aadhaar based instalment for cashless buys by clients called 'Aadhaar Pay' and 'Bharat QR', a coordinated instalment framework utilizing the clients' cell phone to pay through charge or Mastercard by checking a code at the dealer's place and so on., have come to remain.

Anyway with all these progressive new innovations, enhancement in operational efficiencies with the end goal to eventually expand primary concerns and investor esteem will remain a test for all banks. Job of examination and creative income models should be further adjusted. To procure most extreme favourable position in an undeniably advanced society, it is basic that banks must exhibit prevalent execution in all circles of client benefit.

\section{Banking on the Cloud}

Banks are dashing to exploit advertise openings accessible through computerized change. In the meantime, they should deal with the dangers made by the new advanced economy. There is a basic requirement for moderate processing stages that give more noteworthy nimbleness.

There is no uncertainty new advanced advances are changing the managing an account industry. Banks that grasp advancement and receive new advances have remarkable chances to change and enhance how they give money related administrations including offering the capacity to:

1. Collaborate with budgetary innovation accomplices to create computerized items.

2. Provide clients with consistent ongoing, multichannel computerized connections.

3. Simplify and advance business forms through institutionalization, streamlining, and appropriation of cloud arrangements.

4. Build an open and dexterous stage that makes it simple to meet administrative prerequisites.

5. Innovate with troublesome advances like manmade reasoning (AI), IoT, and blockchain.

Rebuilding the plan of action and procedures is basic to any bank's fruitful digitalization. Utilizing imaginative abilities in a cloud sending can accelerate computerized change activities as well as convey extensive process upgrades also.

\section{References}

1. Anna Omarini et al., The digital transformation in banking and the role of FinTechs in the new financial intermediation scenario, Journal of Information Technology, vol. 4, issue 3, pp. 23-28,2017.

2. D S Chaubey et al., The Rise of Digital Banking, Journal of Information Technology, vol. 1, issue 4, pp. 34-39, 2017.

3. A K Rathi et al., Digital Transformation In Banking - The Future Of Banking, Business \& Information Systems Engineering, vol. 57, no. 5, pp. 339-343, 2016.

4. P K Ozili et al., Impact of digital finance on financial inclusion and stability, Borsa Istanbul Review, vol. 3, issue 7, pp. 89-95, 2018.

5. S Lewis et al., Influence of digital banking on customer satisfaction: a case of national bank of Kenya Bungoma county, Journal of Electronic Commerce Research, 7(2), 50-66, 2015.

6. Demirgüç-Kunt, L. KlapperMeasuring financial inclusion: Explaining variation in use of financial services across and within countries, Brookings Papers on Economic Activity, vol. 2013, issue 1, pp. 279-340, 2013.

7. K. Eisenhardt Agency theory: An assessment and review, Academy of Management Review, vol. 14, issue 1, pp. 57-74, 2010. 